Textures and Microstructures, 1988, Vols. 8 \& 9, pp. 173-189

Reprints available directly from the publisher

Photocopying permitted by license only

(C) 1988 Gordon and Breach Science Publishers Inc.

Printed in the United Kingdom

\title{
Effect of Ti on the Development of Rolling Textures in High Purity Iron
}

\author{
HIROSUKE INAGAKI \\ Technical Research Center, Nippon Kokan K.K., 210 Kawasaki-shi, Kawasaki-ku, \\ Minamiwatarida-chou 1-1, Japan
}

(Received 3 July 1987)

\section{Dedicated to the memory of Professor Günter Wassermann}

With the method of the crystallite orientation distribution function analysis, the development of the rolling texture was studied in detail on a Fe-0.004\% $-0.20 \% \mathrm{Ti}$ alloy cold rolled up to $90 \%$ reduction in thickness. It was found that the effect of $\mathrm{Ti}$ was widely different among various rolling texture components. The addition of $\mathrm{Ti}$ enhanced the development of the $\langle 110\rangle \| \mathrm{RD}$ fiber rolling texture component by promoting the rotation about the $\langle 110\rangle \| \mathrm{RD}$ axis. This resulted in the development of the strong $\{112\}\langle 110\rangle$ texture component. As to the $\langle 110\rangle \| \mathrm{TD}$ fiber texture component, it was found that, although the addition of $\mathrm{Ti}$ did not affect the rotation about the $\langle 110\rangle \| \mathrm{TD}$ axis in the range $\{110\}\langle 001\rangle$ to $\{554\}\langle 225\rangle$, it strongly suppressed the rotation of $\{554\}\langle 225\rangle$ into $\{111\}\langle 112\rangle$. As a result, strong $\{554\}\langle 225\rangle$ rolling texture component was developed below $70 \%$ rolling reduction. This component seems to provide origins of the $\{554\}\langle 225\rangle$ recrystallization texture commonly observed in the Ti-stabilized steel. Such changes in the rolling texture would be expected, since slip modes are strongly affected by scavenging of $\mathrm{C}$ atom by $\mathrm{Ti}$, or by the presence of very fine $\mathrm{TiC}$ precipitate particles.

KEY WORDS: Rolling texture, ODF-analysis, iron, titanium-alloyed, crystal rotation.

\section{INTRODUCTION}

It is well known that the addition of $\mathrm{Ti}$ greatly enhances the development of the $\{111\}$ recrystallization texture in low carbon steels. As possible explanations for this, it has been thought that 
solute Ti atoms (Goodenow and Held, 1970), precipitation of the TiC particles (Matsuo and Takahashi, 1971, Fukuda and Shimizu, 1972, 1975) and scavenging of $\mathrm{C}$ atoms by $\mathrm{Ti}$ (Kokubo et al., 1973) play important roles in the formation of the recrystallization texture.

On the other hand, rather little attention had been directed to the effect of Ti on the development of the cold rolling texture (Willis et al., 1975, Matsuo et al., 1972 and V. Schlippenbach et al., 1986). Since this effect might not be so pronounced as to be readily detected by the conventional pole figure method, more reliable and quantitative methods of the texture analysis should be adopted. By using the method of the three dimensional crystallite orientation distribution function analysis (Bunge, 1969), it has been found that the addition of $\mathrm{Ti}$ enhances the development of the $\{112\}\langle 110\rangle$ component in the cold rolling texture (Willis et al., 1975, Matsuo et al., 1972, V. Schlippenbach et al., 1986). In most cases, this has been attributed to the presence of rather strong $\{112\}\langle 110\rangle$ transformation textures in hot bands (Willis et al., 1975 and V. Schlippenbach et al., 1986), and contributions of other factors have not been clarified as yet.

Also rolling reductions adopted in the previous investigations have been limited between 70 (Willis et al., 1975 and Matsuo et al., 1972) and $80 \%$ (V. Schlippenbach et al., 1986), and the effect of rolling reductions has not been studied systematically as yet. For this reason, it is not clear at present how the crystal rotation which occurs during cold rolling is affected by the addition of $\mathrm{Ti}$.

In the previous paper (Inagaki, 1987), it has been found in a $0.05 \% \mathrm{C}$ rimmed steel that the path of this crystal rotation consists of following two branches, i.e., (i) $\{110\}\langle 001\rangle \rightarrow\{554\}\langle 225\rangle \rightarrow$ $\{111\}\langle 112\rangle \rightarrow\{111\}\langle 110\rangle \rightarrow\{332\}\langle 011\rangle$ and (ii) $\{100\}\langle 001\rangle \rightarrow$ $\{100\}\langle 011\rangle \rightarrow\{211\}\langle 011\rangle \rightarrow\{322\}\langle 011\rangle$, both leading to the common $\{322\}\langle 011\rangle$ stable end orientation.

In this investigation, it was tried to clarify how the rate of rotation along these two pathes was affected by the addition of $\mathrm{Ti}$. The influence of the transformation texture was eliminated by using hot bands having weak transformation textures. The effect of the transformation texture on the development of the cold rolling texture was independently evaluated by using hot bands in which strong transformation textures were developed by controlled rolling. 


\section{EXPERIMENTS}

The starting materials used in the present investigation were $150 \mathrm{~kg}$ ingots of high purity $\mathrm{Fe}-0.004 \% \mathrm{C}-0.20 \% \mathrm{Ti}$ and $\mathrm{Fe}-0.023 \% \mathrm{C}-$ $0.13 \% \mathrm{Ti}$ alloys, both melted in a vacuum induction furnace. Contents of other elements were $\mathrm{Mn}, 0.35 \%, \mathrm{P}, 0.002 \%, \mathrm{~S}, 0.001 \%$ and $\mathrm{Al}, 0.032 \%$, respectively. $\mathrm{Fe}-0.004 \% \mathrm{C}-0.20 \% \mathrm{Ti}$ alloy was used to investigate the effect of $\mathrm{Ti}$ on the rate of the crystal rotation which occurs during cold rolling. After slabing, the ingot of this alloy was hot rolled to the thickness of $3 \mathrm{~mm}$. In order to avoid the development of the strong transformation texture, hot rolling was finished at $930^{\circ} \mathrm{C}$. After pickling, the hot bands were cold rolled to 50,70 and $90 \%$ reduction in thickness. Specimens cut from these cold rolled sheets were chemically thinned down to $0.05 \mathrm{~mm}$ thickness. From the $\{110\},\{200\}$ and $\{211\}$ pole figures determined on these specimens, crystallite orientation distribution functions were calculated with the method of Roe up to $l=22$. By comparing orientation distribution functions observed at each rolling reductions with those of the $0.05 \% \mathrm{C}$ rimmed steel (Inagaki, 1987), the effect of $\mathrm{Ti}$ addition on the crystal rotation was quantitatively evaluated.

The effect of the transformation texture on the development of the cold rolling texture was investigated on $\mathrm{Fe}-0.023 \% \mathrm{C}-0.13 \% \mathrm{Ti}$ alloy. By controlled rolling (Inagaki, 1984) this alloy with the finishing temperature of $850^{\circ} \mathrm{C}, 3 \mathrm{~mm}$ thick hot bands having strong transformation textures could be prepared. This alloy was cold rolled $70 \%$ reduction in thickness. By comparing orientation distribution functons of these specimens with those of $\mathrm{Fe}-0.004 \% \mathrm{C}$ $0.20 \% \mathrm{Ti}$ alloy, the effect of the transformation texture was estimated.

\section{RESULTS}

\subsection{Effect of Ti on the crystal rotation}

Figure 1 illustrates $\phi=45^{\circ}$ sections of the crystallite orientation distribution functions observed in Fe- $0.004 \% \mathrm{C}-0.20 \% \mathrm{Ti}$ alloy at each rolling reductions. (Positions of ideal orientations on $\phi=45^{\circ}$ sections are illustrated in detail elsewhere, Inagaki, 1987.) The hot 

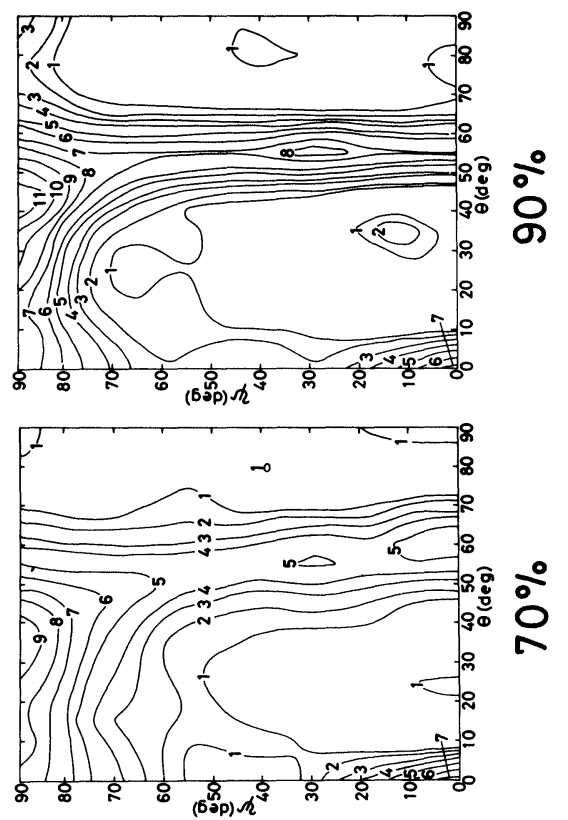

คำ

这

음

$\mathrm{F}$

워

نे

+

ì

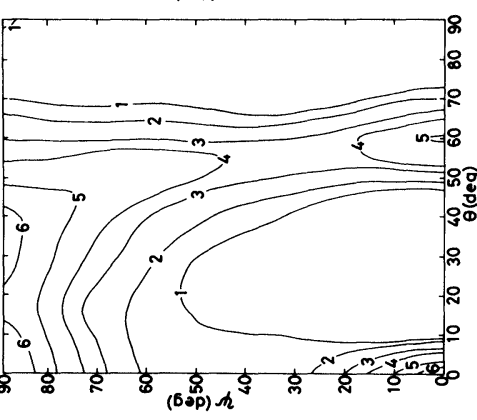

ㅇ

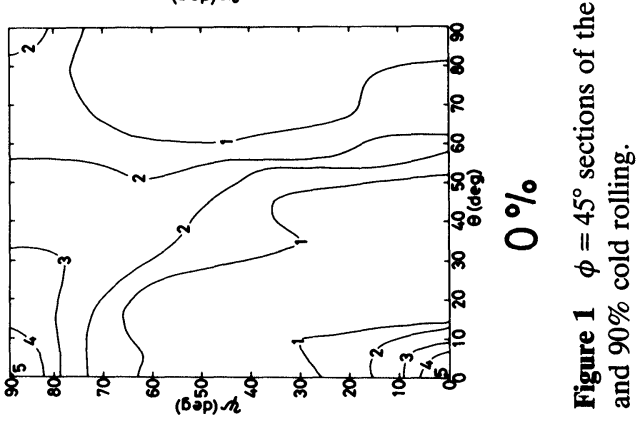


band had a rather strong $\{100\}\langle 011\rangle$ texture. However, components of transformation textures derived from the austenite rolling texture, such as $\{311\}\langle 011\rangle$ and $\{332\}\langle 113\rangle$ (Inagaki, 1977) were considerably weak. Orientation distributions observed at each rolling reductions were qualitatively the same as those observed in $0.05 \% \mathrm{C}$ rimmed steel (Inagaki, 1987). However, intensities of textures were generally much stronger in $\mathrm{Fe}-0.004 \% \mathrm{C}-0.20 \% \mathrm{Ti}$ alloy. These features are more clearly illustrated in Figures 2, 3, 4 and 5 , in which orientation distributions of $\mathrm{Fe}-0.004 \% \mathrm{C}-0.20 \% \mathrm{Ti}$ alloy are directly compared with those of the $0.05 \% \mathrm{C}$ rimmed steel.

Figure 2 shows orientation distributions along $\psi=90^{\circ}$ lines on $\phi=45^{\circ}$ sections given in Figure 1 . Orientations having the $\langle 110\rangle$ axes parallel to the rolling direction (i.e. members of the $\langle 110\rangle \| \mathrm{RD} \dagger$ fiber texture) are all located on this line. In the as hot rolled condition, Figure 2(a), this fiber texture was somewhat stronger in $\mathrm{Fe}-0.004 \% \mathrm{C}-0.20 \% \mathrm{Ti}$ alloy. However, the difference was small. After $50 \%$ rolling reduction, Figure 2(b), orientations in the range $\{100\}\langle 011\rangle$ to $\{111\}\langle 110\rangle$ showed much more remarkable development in $\mathrm{Fe}-0.004 \% \mathrm{C}-0.20 \% \mathrm{Ti}$ alloy. Between these two specimens, the difference in these components became largest at $70 \%$ rolling reduction, Figure 2 (c).

At $90 \%$ rolling reduction, Figure 2(d), the difference became smaller again. However, throughout the orientation range between

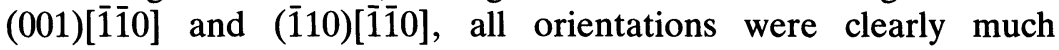
stronger in $\mathrm{Fe}-0.004 \% \mathrm{C}-0.20 \% \mathrm{Ti}$ alloy than in $0.05 \% \mathrm{C}$ rimmed

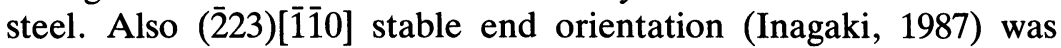
much more well-developed in Fe-0.004\%C-0.20\% Ti alloy.

From these results, it is clear that, even in the absence of the strong $\{112\}\langle 110\rangle$ component in hot bands, strong $\langle 110\rangle \|$ RD fiber rolling texture, above all $\{211\}\langle 011\rangle$ rolling texture component can be developed by the addition of Ti.

Figure 3 shows orientation distributions along $\psi=0^{\circ}$ lines on $\phi=45^{\circ}$ sections given in Figure 1. All orientations having the $\langle 110\rangle$ axes parallel to the transverse direction and lying in the range (001)[110] to (110)[001] (i.e., members of the $\langle 110\rangle \| \mathrm{TD}$ fiber textures) are located on the line.

\footnotetext{
$\dagger$ In this paper, RD, TD and ND denote rolling, transverse and normal directions, respectively.
} 

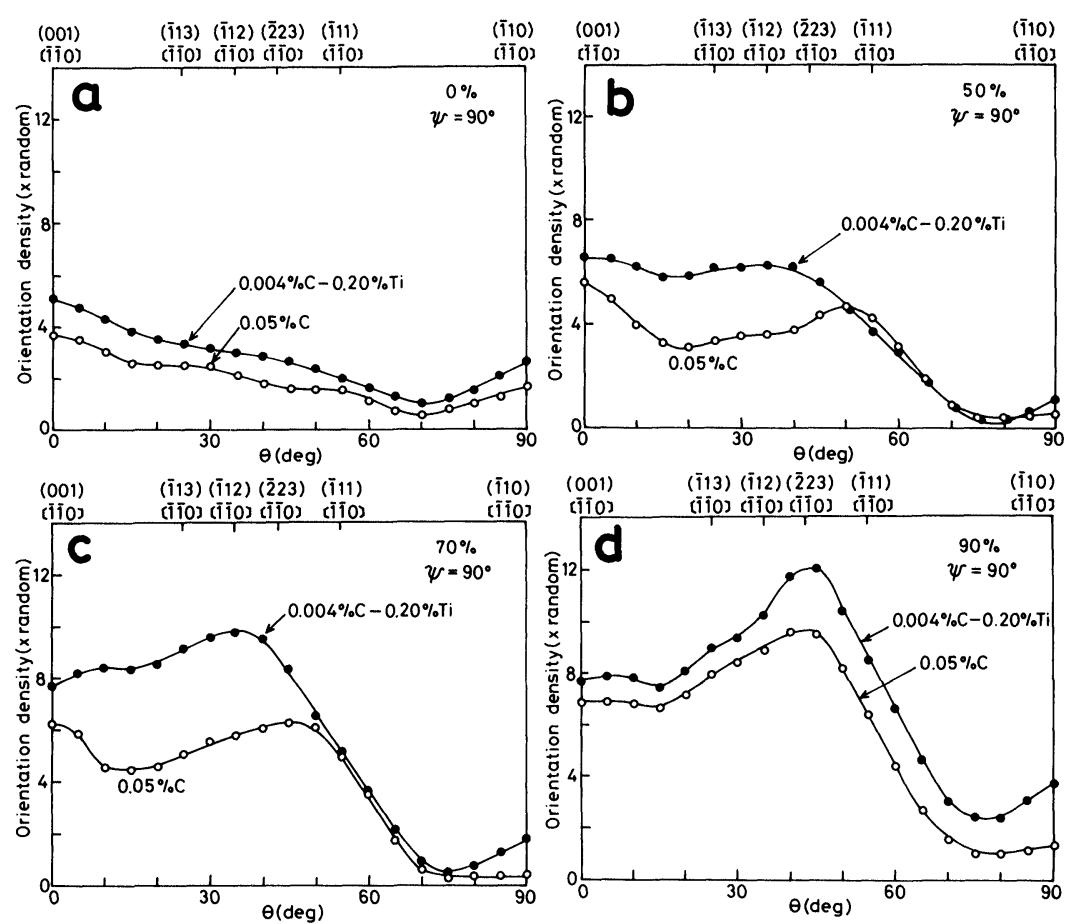

Figure 2 Orientation distributions along $\psi=90^{\circ}$ line on $\phi=45^{\circ}$ sections given in Figure 1. Rolling reductions; a) $0 \%$ (as hot rolled), b) $50 \%$, c) $70 \%$ and d) $90 \%$, respectively.

In the as hot rolled condition, Figure $3(\mathrm{a}), 0.05 \% \mathrm{C}$ rimmed steel had a uniform orientation distribution between (111)[112] and (110)[001], whereas $\mathrm{Fe}-0.004 \% \mathrm{C}-0.20 \% \mathrm{Ti}$ alloy showed in this range a broad peak whose center was located at about $(\overline{5} 54)[2 \overline{2} 5]$ orientation. Since orientations near $(\overline{5} 54)[2 \overline{2} 5]$ would be derived from the $\mathrm{Cu}$ type rolling texture in the austenite phase via Kurdjmov-Sachs relationship (Inagaki, 1977), these results suggest that some of the austenite in $\mathrm{Fe}-0.004 \% \mathrm{C}-0.20 \% \mathrm{Ti}$ were not recrystallized. In this hot band, however, strong (001)[1 $1 \overline{1} 0]$ and

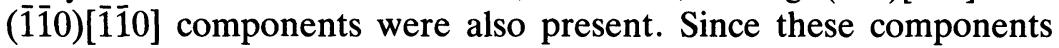
would be derived from the austenite recrystallization texture via 

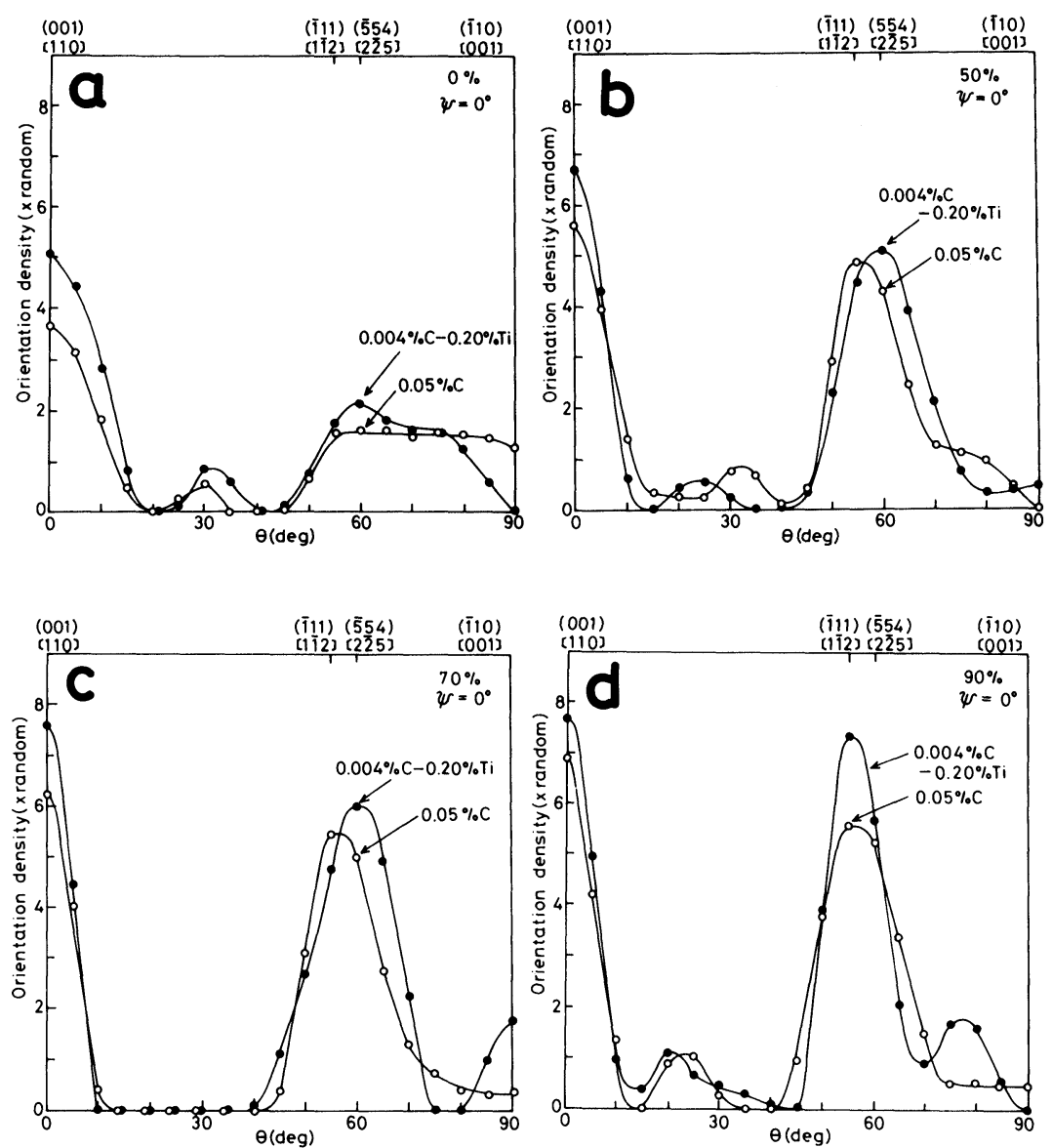

Figure 3 Orientation distributions along $\psi=0^{\circ}$ line on $\phi=45^{\circ}$ sections given in Figure 1. Rolling reductions; a) $0 \%$ (as hot rolled), b) $50 \%$, c) $70 \%$ and d) $90 \%$, respectively.

Kurdjmov-Sachs relationship (Inagaki 1977), it might be concluded that most of the austenite were recrystallized in this hot band.

After 50\% cold rolling, Figure 3(b), crystal rotation occurred in both specimens about the $\langle 110\rangle$ axis lying parallel to the transverse directions, forming distinct peaks at $\theta=55$ or $60^{\circ}$. However, this rotation seemed to occur more readily in $0.05 \% \mathrm{C}$ rimmed steel than 
in $\mathrm{Fe}-0.004 \% \mathrm{C}-0.20 \% \mathrm{Ti}$ alloy. In the former case, the peak was located at (111)[112], whereas in the latter case, it was located at (554)[22̄5]. The height of the peak was nearly the same in both cases.

After 70\% cold rolling, Figure 3(c), both peaks increased their heights appreciably. This increase was much larger in $\mathrm{Fe}-0.004 \% \mathrm{C}$ $0.20 \% \mathrm{Ti}$ alloy. Positions of peaks, however, did not show any change. It should be noted that $(\overline{5} 54)[2 \overline{2} 5]$ orientation was quite stable in $\mathrm{Fe}-0.004 \% \mathrm{C}-0.20 \% \mathrm{Ti}$ alloy. In this alloy, rotation about the $\langle 110\rangle \| \mathrm{TD}$ axis beyond (554)[225] orientation seems to be strongly suppressed. Further rotation about the $\langle 110\rangle \| \mathrm{TD}$ axis toward (i11)[112] occurred only after $90 \%$ cold rolling, Figure $3(d)$.

Figure 4 shows orientation distributions along $\theta=55^{\circ}$ line on $\phi=45^{\circ}$ sections given in Figure 1. All orientations having $\langle 111\rangle$ axes parallel to the normal direction (i.e., members of the $\langle 111\rangle \| N D$ fiber texture) are located on this line. Below $70 \%$ rolling reduction, no marked difference was observed between $0.05 \% \mathrm{C}$ rimmed steel and $\mathrm{Fe}-0.004 \% \mathrm{C}-0.20 \% \mathrm{Ti}$ alloy. In both cases, rather uniform orientation distributions were observed after $70 \%$ cold rolling, indicating the formation of the uniform $\langle 111\rangle \| N D$ fiber
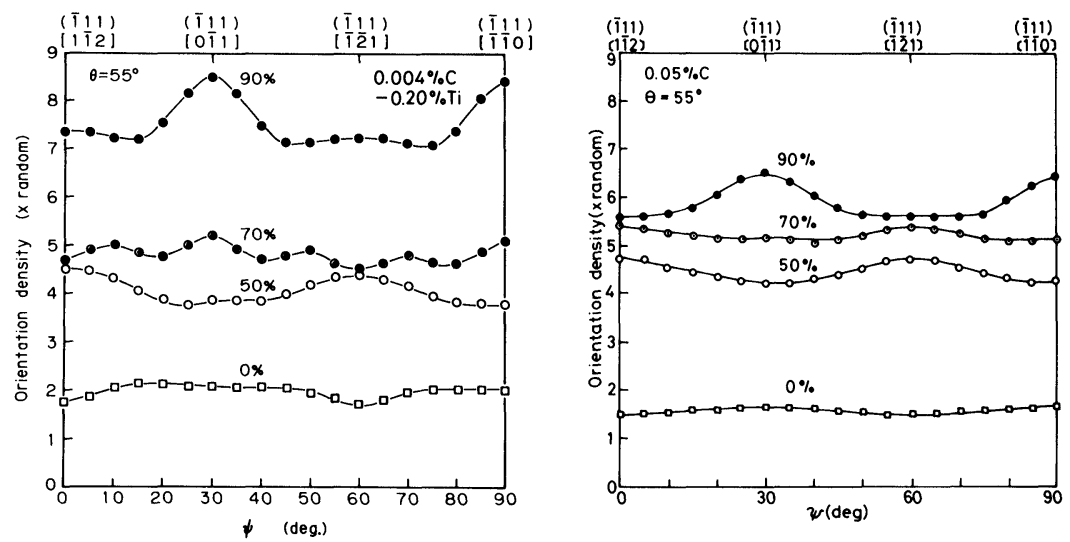

\section{a) $\mathrm{Fe}-0.004 \% \mathrm{C}-0.20 \% \mathrm{Ti}$ alloy b) $0.05 \% \mathrm{C}$ rimmed steel}

Figure 4 Orientation distributions along $\theta=55^{\circ}$ line on $\phi=45^{\circ}$ sections given in Figure 1. a) Fe-0.004\% C-0.20\% Ti alloy, b) $0.05 \% \mathrm{C}$ rimmed steel. 
texture. After $90 \%$ cold rolling, $\{111\}\langle 011\rangle$ orientations became in both cases the main orientation among the members of the $\langle 111\rangle \| N D$ fiber texture. But it should be noted in the case of $\mathrm{Fe}-0.004 \% \mathrm{C}-0.20 \% \mathrm{Ti}$ alloy that, above $70 \%$ rolling reduction, all members of the $\langle 111\rangle \| N D$ fiber texture increased their intensities appreciably.

\subsection{Effect of the transformation texture}

In Figure $5, \phi=45^{\circ}$ sections of the crystallite orientation distribution functions observed in hot bands of $\mathrm{Fe}-0.004 \% \mathrm{C}-0.20 \% \mathrm{Ti}$ and $\mathrm{Fe}-0.023 \% \mathrm{C}-0.13 \% \mathrm{Ti}$ alloys are compared. It is evident that crystallite orientation distribution functions are quite different between these two alloys.

This is more clearly shown in Figures 6 and 7. Figure 6 shows orientation distributions along $\psi=90^{\circ}$ line on $\phi=45^{\circ}$ sections given in Figure 5. In $\mathrm{Fe}-0.023 \% \mathrm{C}-0.13 \% \mathrm{Ti}$ alloy, a distinct peak

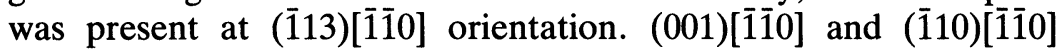
were much weaker than in $\mathrm{Fe}-0.004 \% \mathrm{C}-0.20 \% \mathrm{Ti}$ alloy.
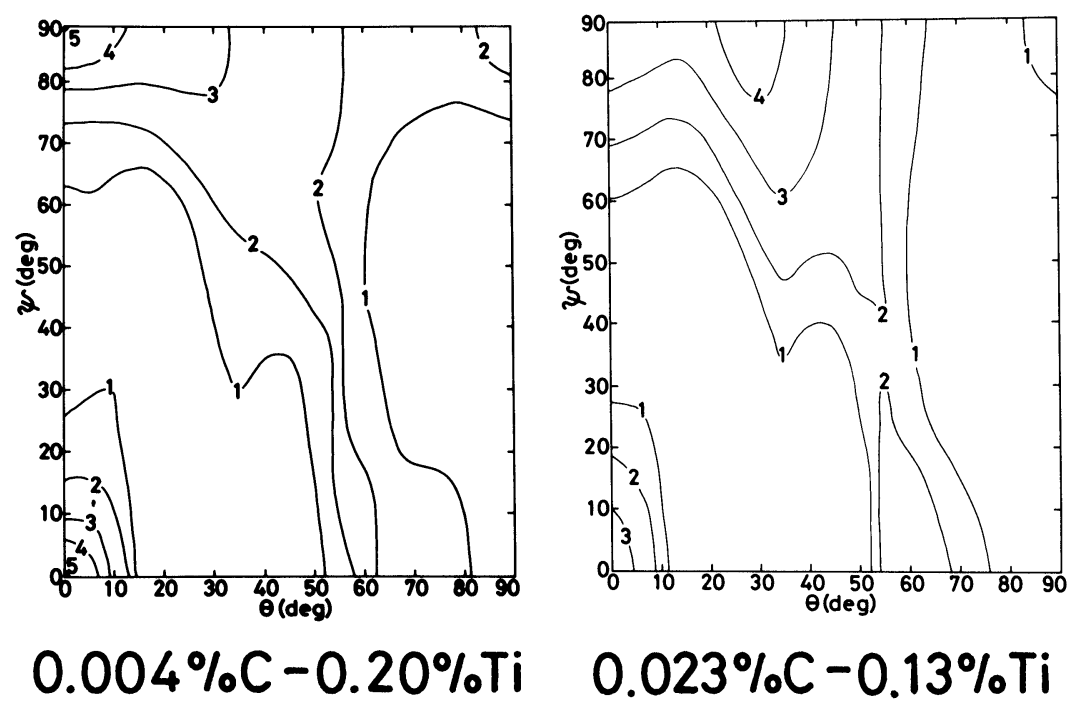

Figure $5 \phi=45^{\circ}$ sections of the crystallite orientation distribution functions observed in the hot bands of $\mathrm{Fe}-0.004 \% \mathrm{C}-0.20 \% \mathrm{Ti}$ and $\mathrm{Fe}-0.023 \% \mathrm{C}-0.13 \% \mathrm{Ti}$ alloys. 


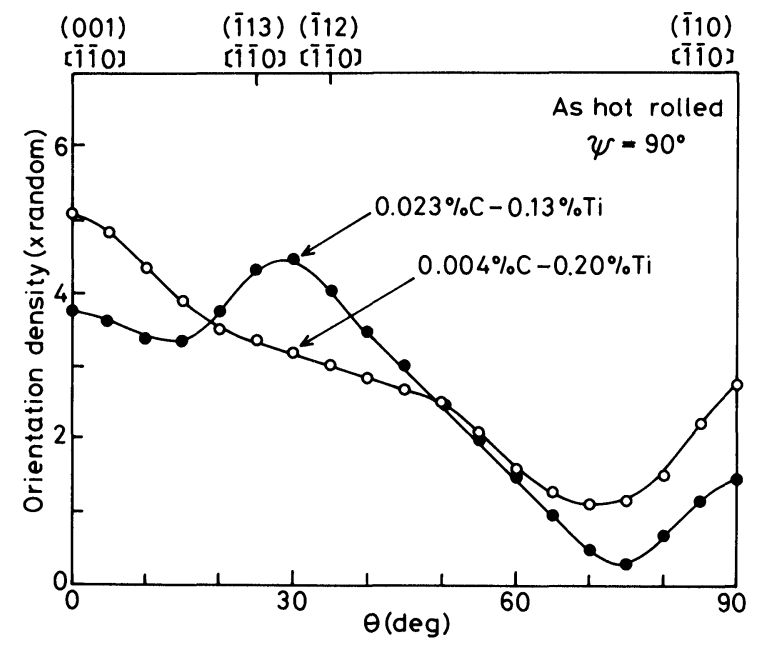

Figure 6 Orientation distributions along $\psi=90^{\circ}$ line on $\phi=45^{\circ}$ sections given in Figure 5.

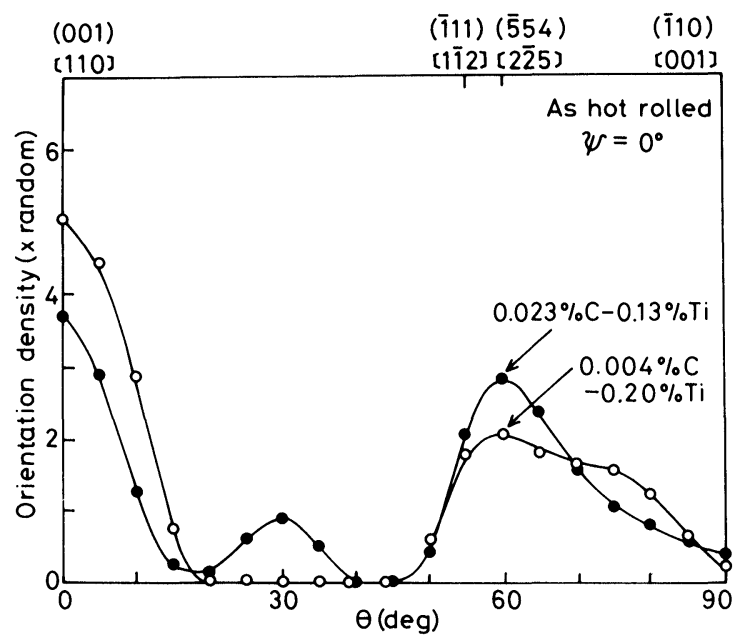

Figure 7 Orientation distributions along $\psi=0^{\circ}$ line on $\phi=45^{\circ}$ sections given in Figure 5. 
Figure 7 illustrates orientation distributions along $\psi=0^{\circ}$ line on $\phi=45^{\circ}$ sections given in Figure 5. In Fe-0.023\%C-0.13\% Ti alloy, a strong peak was present at $(\overline{5} 54)[2 \overline{2} 5]$ orientation.

Thus, it is evident that the hot bands of $\mathrm{Fe}-0.023 \% \mathrm{C}-0.13 \% \mathrm{Ti}$ alloy had a relatively strong texture consisting of $\{554\}\langle 225\rangle$ and $\{311\}\langle 011\rangle$ main orientations. These are components of the transformation textures derived from the Cu-type austenite rolling texture via Kurdjumov-Sachs relationship (Inagaki, 1977). In this alloy, recrystallization of the austenite might have been more effectively suppressed than in $\mathrm{Fe}-0.004 \% \mathrm{C}-0.20 \% \mathrm{Ti}$ alloy, since volume fraction of $\mathrm{TiC}$ particles precipitated was larger because of higher $\mathrm{C}$ content. In addition to this, since controlled rolling with the lower finishing temperature was adopted in hot rolling, austenite rolling texture developed in this alloy might have beeen much stronger. As a result, transformation textures inherited from these austenite rolling textures were much stronger in this alloy. Figure 8 shows $\phi=45^{\circ}$ sections of the crystallite orientation distribution functions observed after $70 \%$ cold rolling. At first glance it is clear that the rolling texture is weaker in $\mathrm{Fe}-0.023 \% \mathrm{C}-0.13 \% \mathrm{Ti}$ alloy than
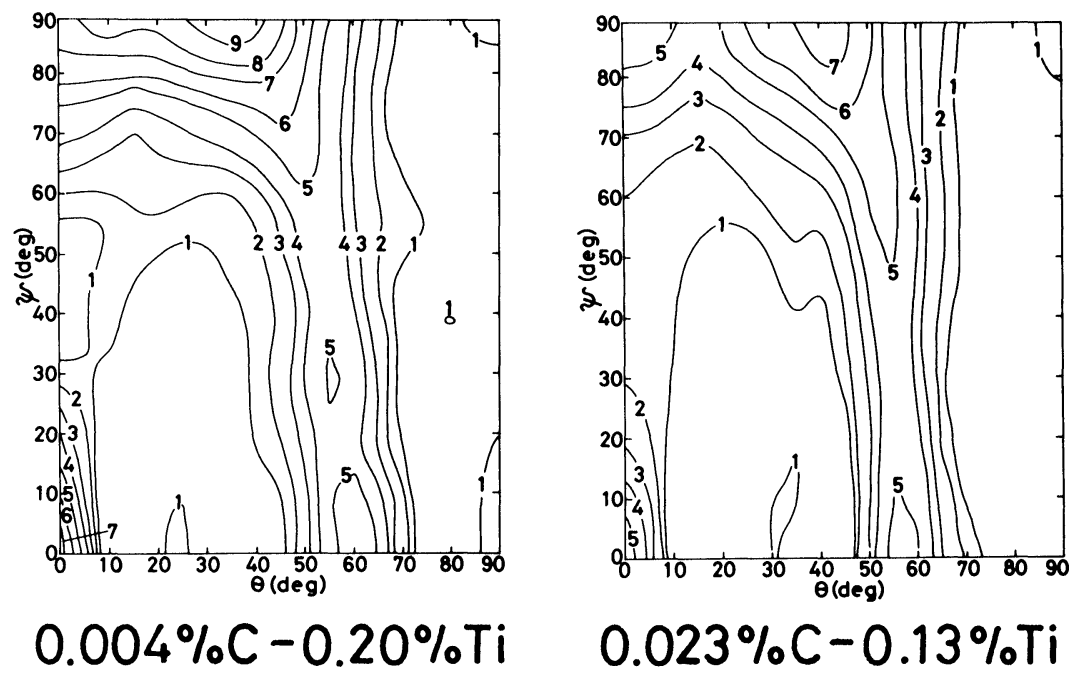

Figure $8 \phi=45^{\circ}$ sections of the crystallite orientation distribution functions observed in $\mathrm{Fe}-0.004 \% \mathrm{C}-0.20 \% \mathrm{Ti}$ and $\mathrm{Fe}-0.023 \% \mathrm{C}-0.13 \% \mathrm{Ti}$ alloys after $70 \%$ cold rolling. 


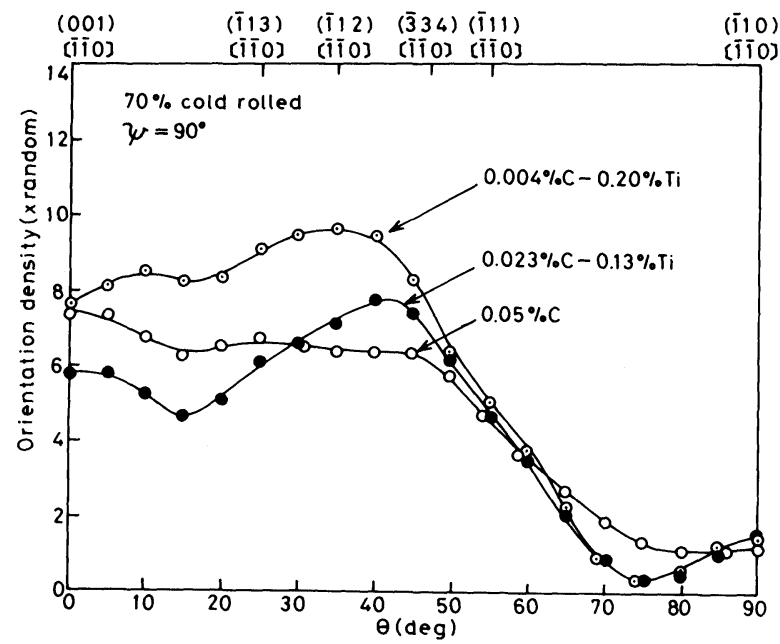

Figure 9 Orientation distributions along $\psi=90^{\circ}$ line on $\phi=45^{\circ}$ sections given in Figure 8 .

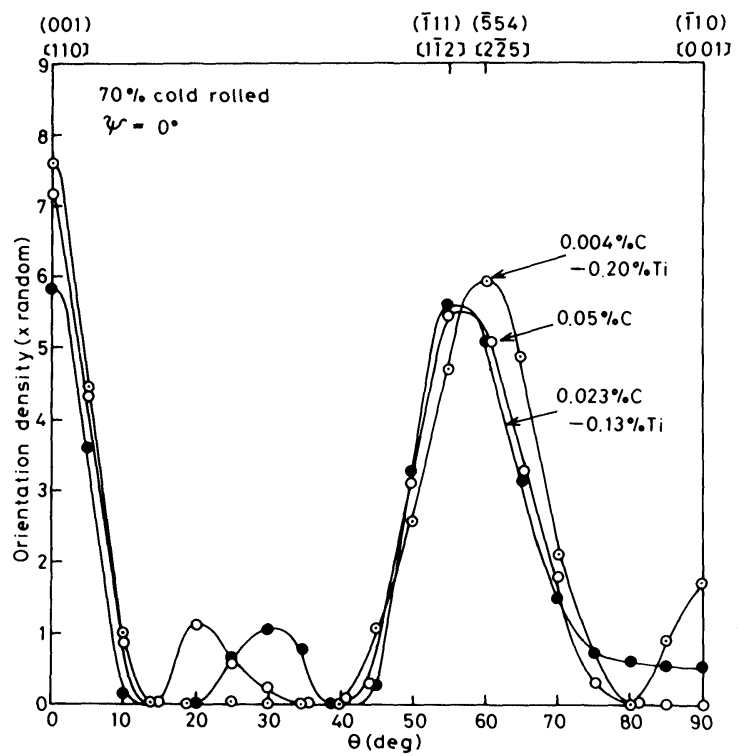

Figure 10 Orientation distributions along $\psi=0^{\circ}$ line on $\phi=45^{\circ}$ sections given in Figure 8. 
in Fe-0.004\% C- $0.20 \% \mathrm{Ti}$ alloy. Orientation distributions along $\psi=$ $90^{\circ}$ line on these $\phi=45^{\circ}$ sections are shown in Figure 9. It should be noted that orientations in the range between (001)[1iㅣㄹ and (111)[110] were not well developed in Fe-0.023\% C-0.13\% Ti alloy. In this alloy, orientations in the range between (001)[1 $\overline{1} 10]$ and $(\overline{1} \overline{1} 2)[\overline{1} \overline{1} 0]$ were even weaker than in $0.05 \% \mathrm{C}$ rimmed steel.

Figure 10 shows orientation distributions along $\psi=0^{\circ}$ line on $\phi=45^{\circ}$ sections given in Figure 8. Orientation distributions in $\mathrm{Fe}-0.023 \% \mathrm{C}-0.13 \% \mathrm{Ti}$ alloy had a maximum at (111)[112] orientation. However, both the height and position of this maximum were the same as those observed in the $0.05 \% \mathrm{C}$ rimmed steel.

From these results, it is evident that the addition of excess amount of $C$ smears out the strong development of $\{112\}\langle 110\rangle$ and $\{554\}\langle 225\rangle$ rolling texture components observed in $\mathrm{Fe}-0.004 \% \mathrm{C}$ $0.20 \% \mathrm{Ti}$ alloy).

\section{DISCUSSION}

With the crystallite orientation distribution function analysis, it has already been found that the addition of $\mathrm{Ti}$ enhances the development of the $\{112\}\langle 110\rangle$ component of the rolling texture in low carbon steels cold rolled 70 to $80 \%$ (Willis, 1975, Matsuo et al., 1972, V. Schlippenbach et al., 1986). Similar observations have been made also in Nb stabilized steels (Willis et al., 1975 and Hook et al., 1975). Hook, Heckler and Ellias studied the effect of $\mathrm{Nb}$ addition on the development of the rolling texture in $\mathrm{Fe}-0.005 \% \mathrm{C}$ alloy cold rolled $60 \%$. They found that the $\{112\}\langle 110\rangle$ rolling texture component increased remarkably with the increasing $\mathrm{Nb}$ content. Since the rolling reduction adopted in these investigations have been limited between 60 and $80 \%$, it is not clear at present how the whole rotation pathes are affected by the addition of $\mathrm{Ti}$ or $\mathrm{Nb}$. By varying the rolling reduction in wide range and by following the rotation of various rolling texture components systematically, it was found in the present investigation that not only the development of the $\langle 110\rangle \| \mathrm{RD}$ fiber rolling texture, but also the development of the $\langle 110\rangle \| \mathrm{TD}$ fiber rolling texture were strongly affected by the addition of Ti. Since these effects of $\mathrm{Ti}$ are widely different 
between these two fiber rolling texture components, they will be discussed separately below.

\section{$4.1\langle 110\rangle \| R D$ fiber rolling texture}

Development of the strong $\{112\}\langle 110\rangle$ component in the rolling texture of $\mathrm{Ti}$ and $\mathrm{Nb}$ steels have been attributed in the past investigations to the presence of strong $\{112\}\langle 110\rangle$ transformation texture in hot hands (Willis et al., 1975, V. Schlippenbach et al., 1986 and Hook et al., 1975). It has been considered that cold rolling results in the reinforcement of this component, since it is the stable end orientation of cold rolling (Hook et al., 1975). It is wellknown in the case of control-rolled low carbon microalloyed steels that such transformation textures can be developed appreciably, if recrystallization of austenite is suppressed by the precipitation of $\mathrm{NbC}$ or $\mathrm{TiC}$, and if heavy rolling reductions are given to the unrecrystallized austenite (Inagaki, 1977). The austenite rolling texture developed through this processing is supposed to be $\mathrm{Cu}$ type, and the main orientations of the transformation texture derived from this austenite rolling texture via Kurdjmov-Sachs relationship were identified, in the case of $0.1 \% \mathrm{C}-1.3 \% \mathrm{Mn}$ $0.04 \% \mathrm{Nb}$ steel, to be $\{311\}\langle 011\rangle$ and $\{322\}\langle 113\rangle$ (Inagaki, 1977). Although previous investigations have identified one of the main orientations of the transformation texture as $\{211\}\langle 011\rangle$, $\{311\}\langle 011\rangle$ seems to be better description of this component. This is also evident from Figure 6. In very low $\mathrm{C}$ steel, $\{332\}\langle 113\rangle$ component seems to be better described as $\{554\}\langle 225\rangle$. This is also evident from Figure 7, although spread of orientation distribution about this orientation is large.

It is readily understood that strong $\{112\}\langle 110\rangle$ rolling texture component can be developed by cold rolling hot bands containing strong $\{311\}\langle 011\rangle$ transformation texture, since $\{211\}\langle 011\rangle$ and $\{311\}\langle 011\rangle$ are only $10^{\circ}$ apart, and since $\{211\}\langle 011\rangle$ is located on the rotation path toward the $\{322\}\langle 011\rangle$ stable end orientation (Inagaki, 1987). In the case of $\mathrm{Fe}-0.004 \% \mathrm{C}-0.20 \% \mathrm{Ti}$ alloy, however, $\{311\}\langle 011\rangle$ transformation texture component was not well developed in hot bands, Figures 2 and 6, since finishing temperature of hot rolling was intentionally selected to be above the recrystallization temperature of the austenite. In spite of this, 
development of the strong $\{112\}\langle 110\rangle$ rolling texture component could be observed in this alloy cold rolled above $50 \%$ reduction in thickness. Development of the strong $\{112\}\langle 110\rangle$ rolling texture component cannot be explained therefore with the mechanism described above. It seems that either absence of solute carbon atom, or presence of fine $\mathrm{TiC}$ or $\mathrm{NbC}$ particles in hot bands enhances the slip rotation which results in the development of the strong $\{112\}\langle 110\rangle$ rolling texture component.

In ultra low carbon Ti stabilized steels, it has been confirmed that very fine $\mathrm{TiC}$ particles are already precipitated in hot bands (Matsuoka and Takahashi, 1971, Fukuda and Shimizu, 1972). Also, the results of internal friction measurements have indicated that solute $\mathrm{C}$ atoms are absent in these hot bands due to the scavenging effect of Ti atom (Fukuda and Shimizu, 1972).

In the case of $\mathrm{Fe}-0.023 \% \mathrm{C}-0.13 \% \mathrm{Ti}$ alloy, it is interesting to note that, although strong $\{311\}\langle 011\rangle$ transformation texture component was developed in the hot band, $\langle 110\rangle \| \mathrm{RD}$ fiber rolling texture observed after $70 \%$ rolling was quite weak. It has been observed that, in $\mathrm{Ti}$ stabilized steel with higher $\mathrm{C}$ content, $\mathrm{TiC}$ particles precipitated in the hot band are relatively coarse (Matsuoka and Takahashi, 1971). Presence of these coarse particles might have randomized the cold rolling texture.

From these results, it might be concluded that, although the presence of $\{311\}\langle 011\rangle$ transformation texture component in the hot band may be favourable to the development of $\{112\}\langle 110\rangle$ component in the rolling texture, it is not a necessary condition, at least at higher rolling reductions.

\section{$4.2\langle 110\rangle \|$ TD fiber rolling texture}

From Figure 3, it is clear that, in Fe-0.004\%C-0.20\% Ti alloy, the rotation of crystals from $\{554\}\langle 225\rangle$ to $\{111\}\langle 112\rangle$ orientations was strongly suppressed below $70 \%$ rolling reduction. As a result, a strong stable peak was formed at the $\{554\}\langle 225\rangle$ orientation. Since crystals in this orientation would be severely strained, it is expected that, on annealing these specimens, strong $\{554\}\langle 225\rangle$ recrystallization texture would be developed. This is in fact just what has been observed (Willis et al., 1975, V. Schlippenbach et al., 1986, Akisue and Takashima, 1973). The mechanism through which 
the rotation of the $\{554\}\langle 225\rangle$ orientation into the $\{111\}\langle 112\rangle$ orientation is suppressed, is not clear at present. However, presence of very fine $\mathrm{TiC}$ precipitate particles seems to play here an important role.

Above $70 \%$ rolling reduction, such barrier to the crystal rotation from $\{554\}\langle 225\rangle$ to $\{111\}\langle 112\rangle$ was completely eliminated, and since all of these strong $\{554\}\langle 225\rangle$ orientations are rotated into $\{111\}\langle 112\rangle$, and further into $\{111\}\langle 110\rangle$ orientations, $\langle 111\rangle \| N D$ fiber texture which is much stronger than that observed in the $0.05 \% \mathrm{C}$ rimmed steel was developed.

Thus, it might be concluded that, below $70 \%$ rolling reduction, the addition of $\mathrm{Ti}$ enhances the development of the $\{554\}\langle 225\rangle$ orientation by suppressing the rotation of the $\{554\}\langle 225\rangle$ orientation into the $\{111\}\langle 112\rangle$ orientation.

In Fe-0.023\% C- $0.13 \% \mathrm{Ti}$ alloy, however, such effect of $\mathrm{Ti}$ could not be observed. This might be also ascribed to the large amount of coarse $\mathrm{TiC}$ particles precipitated in the hot band of this alloy.

\section{CONCLUSIONS}

The addition of $\mathrm{Ti}$ significantly affects the development of the rolling texture in high purity iron. This effect is widely different among various components of the rolling texture.

(1) $\langle 110\rangle \| \mathrm{RD}$ fiber rolling texture components; The addition of Ti enhances the rotation of these components about the $\langle 110\rangle 11 \mathrm{RD}$ axis. This leads to the development of the strong $\{112\}\langle 110\rangle$ rolling texture component.

(2) $\langle 110\rangle \| \mathrm{TD}$ fiber rolling texture components; In the orientation range between $\{110\}\langle 001\rangle$ and $\{554\}\langle 225\rangle$, the addition of $\mathrm{Ti}$ does not significantly affect the rotation of these components about the $\langle 110\rangle \| \mathrm{TD}$ axis. However, the rotation of the $\{554\}\langle 225\rangle$ orientation into the $\{111\}\langle 112\rangle$ orientation is strongly suppressed by the addition of $\mathrm{Ti}$. This results in the development of the strong $\{554\}\langle 225\rangle$ rolling texture component.

Thus, the rolling texture of the Ti-stabilized steel can be characterized by the strong $\{554\}\langle 225\rangle$ and $\{112\}\langle 110\rangle$ components. 


\section{References}

1. Akisue, O. and Takashina, K. (1973) Trans. Japan Inst. Metals, 14, p. 489.

2. Bunge, H. J. (1969) Mathematische Methoden der Texturanalyse, Akademie Verlag, Berlin.

3. Emren, F., Von Schlippenbach, U. and Lücke, K. (1986) Acta Metall, 34, p. 2105.

4. Fukuda, N. and Shimizu, M. (1972) Sosei-to-Kakou, 13, p. 841.

5. Fukuda, N. and Shimizu, M. (1975) Tetsu-to-Hagane, 61, p. 817.

6. Goodenow, R. H. and Held, J. F. (1970) Metal Trans., 1, p. 2507.

7. Hook, R. E., Heckler, A. J. and Ellias, A. J., (1975) Metal. Trans., 6A, p. 1683.

8. Inagaki, H. (1977) Trans. Iron Steel Inst. Japan, 17, p. 166.

9. Inagaki, H. (1984) Zeit. Metallkunde, 75, p. 510.

10. Inagaki, H. (1987) Zeit. Metallkunde, 78, No. 6, p. 431.

11. Karlyn, D. A., Vieth, R. W. and Forand, J. L. (1969) Mechanical Working and Processing, AIME, New York, VII, p. 127.

12. Kokubo, I., Sudo, M., Kameno, M., Hashimoto, S., Tsukatani, I. and Iwai, T., (1973) Tetsu-to-Hagane, 59, p. 469.

13. Matsuo, M., Hayami, S. and Tani, S. (1972) Seitetsu Kenkyu, 276, p. 10207.

14. Matsuoka, T. and Takahashi, M. (1971) Tetsu-to-Hagane, 57, p. 1134.

15. Roe, R. J. (1965) 36, p. 2024.

16. Von Schlippenbach, U., Emren, F. and Lücke, K. (1986) Acta Metall. 34, p. 1289.

17. Suzuki, T., (1984) Proc. 7th Int. Conf. on Texture of Materials, Netherlands Soc. for Material Science, p. 439.

18. Terasaki, F. and Kaneko, T. (1972) Tetsu-to-Hagane, 58, p. 1674.

19. Willis, D. J., Hocking, K. and Harthley, M. (1975) J. of Australian Inst. Metals, 20, p. 101. 